\title{
Simple Test Evaluator based on multiple choice questions for Universities with a limited Budget
}

\section{Evaluador Simple de Exámenes con base a preguntas de opción multiple para las Uníversidades con presupueto límitado}

URUETA, Daniel†*, RÍOS, David, ALANÍS, Reynaldo and MOTA, Juan

Universidad Politécnica del Estado de Guerrero

ID $1^{\text {st }}$ Author: Daniel, Urueta / ORC ID: 0000-0002-8741-6978

ID $1^{\text {st }}$ Coauthor: David, Rios / ORC ID: 0000-0002-0494-7045

ID $2^{\text {nd }}$ Coauthor: Reynaldo, Alanís / ORC ID: 0000-0001-5397-7016

ID $3^{\text {rd }}$ Coauthor: Juan, Mota / ORC ID: 0000-0001-6099-9408

DOI: 10.35429/EJC.2019.8.5.1.5

Received April 08, 2019; Accepted May 30, 2019

\begin{abstract}
Nowadays, data management has grown exponentially. A specific case is the few universities with limited resources that each year make a new entry process, in which hundreds of answer sheets are generated and evaluated by hand. In this context, automating the evaluation of characters implies an important saving of human resources and time; what it entails in an increase in productivity. The purpose of this document is to present a proposal with a simple methodology to be able to create a program that automatically evaluates exam answers sheets, which will improve the delivery time of partial and final grades.
\end{abstract}

Computer vision, Optical recognition, Automatic evaluator

\begin{abstract}
Resumen
En la actualidad, el manejo de datos ha crecido exponencialmente. Un caso concreto son las algunas universidades con recursos limitados que cada año hacen un proceso de nuevo ingreso, en los cuales cientos de hojas de respuestas son generadas y evaluadas a mano. En este contexto, automatizar la evaluación de caracteres implica un importante ahorro de recursos humanos y tiempo; lo que conlleva en un aumento en la productividad. El presente documento tiene como finalidad presentar una propuesta con una metodología simple poder crear un programa que evalúe automáticamente hojas de respuestas de exámenes con lo cual se logrará mejorar el tiempo de entrega de calificaciones parciales y finales.
\end{abstract}

Visión por computadora, Reconocimiento óptico, Evaluador automático

Citation: URUETA, Daniel, RÍOS, David, ALANÍS, Reynaldo and MOTA, Juan. Simple Test Evaluator based on multiple choice questions for Universities with a limited Budget. Journal-Republic of Colombia. 2019 5-8: 1-5

\footnotetext{
* Correspondence to Author (email: crownirv@ gmail.com)

$\dagger$ Researcher contributing as first author.
} 


\section{Introduction}

The research instruments to obtain representative information of a group of people such as: questionnaires, interviews, surveys, exams, etc., are frequently handled by companies and institutions. you get them from: questionnaires, interviews, surveys, exams, etc. This type of instruments are usually applied through the use of paper and rarely digitally, this causes a certain volume of information to analyze and evaluate later; the information collected is digitized in order to store the survey data, causing a loss of time. In this context, automating the detection of characters implies an important human resources and time savings; what it entails in an increase in productivity. At the same time, the quality of the service can be improved, avoiding human errors.

To evaluate each answer sheet it is necessary to recognize each mark on it, relate it to an answer and compare it with a correct answer for each question, systems for the recognition of marks in exams, require special sheets with many marks of reference and synchronization, in this systems, the answer sheets are introduced to a dedicated scanner which emits a light from one side of the sheet and measures the intensity with which it passes through the paper detecting variations in where the marks are. The results are good and fast, but it depends on the format that each manufacturer establishes, the purchase of special copyrighted material and access to the corresponding scanner. However, with the mobile technology advance, the decrease in price and an increased of its capabilities; it is possible to implement Optical Mark Recognition (ORM) through software algorithms, which by means of a photograph are able to recognize the marks In the answer sheets, identify with which option they are related and compare with the correct answers.

Although in the literature there are some proposals for the automatic evaluation of answer sheets based on computer vision, it is worth mentioning that these have license costs either for their use or based on the software necessary for its construction and operation. Therefore, creating a method not only simple but also without associated costs for the use of those who can not pay the cost is necessary for anyone to make use of it.
The following sections detail the theory behind the methods used in the proposal and in turn the subsequent construction and start-up methodology. Finally, the results obtained and the conclusions are shown.

\section{Objectives}

- Develop software with computer vision for the automatic evaluation of answer sheets with ítems

- Design a simple and friendly user interface

- $\quad$ Evaluate software and verify its accuracy and precision

\subsection{Concepts and definitions}

\subsubsection{Capture and Acquisition of images}

The process of capturing the image refers to the way in which it will be obtained, either through a digital camera, a scanner or some other device.

\subsubsection{Preprocessing}

This stage includes techniques for binarization, noise reduction, contrast enhancement, among others. To do this, various filters are applied to the images.

Filtering techniques are methods of highlighting or suppressing, selectively, information contained in an image, to highlight some elements of the image, or to hide anomalous values.

\subsubsection{Contrast enhancement}

\subsubsection{Grayscale}

The gray scale is the representation of an image in which each pixel is drawn using an individual numerical value that represents its luminance, on a scale that ranges between black and white. In this, when dealing with JPG-type images, the RGB value of their colors is averaged and the average is assigned as a new RGB value, resulting in a grayscale image. 

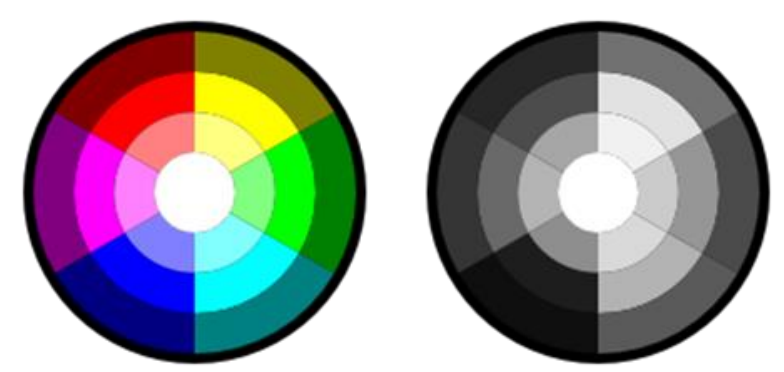

Figure 1 Comparison between the original color image and its conversion to grayscale

\subsubsection{Noise reduction}

\subsubsection{Filters step bass}

It aims to soften the image, they are useful when it is assumed that the image has lots of noise and you want to delete. They can also be used to highlight the information corresponding to a particular scale (size of the filter array); for example, in the event that want to eliminate variability associated with the types of cover in the image thus standardising its response.

\subsubsection{The median filter}

It has the advantage that the final value of the pixel is a real value present in the image and not an average, this reduces the blur effect that have images that have suffered a media filter.

In addition, the median filter is less sensitive to outliers. The drawback is that it is more complex to calculate since there to sort different values that appear in the pixels included in the window and determine what the core value.

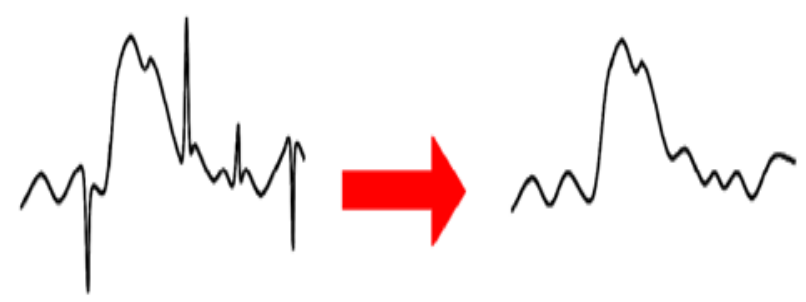

Figure 2 After applying a filter medium in a vicinity of \pm 3 samples

\subsubsection{Description}

At this stage, convenient features are obtained to differentiate brands, like the shape, size, area, etc.

\subsubsection{Hough's Transform}

The Hough transform was proposed by Paul Hough, initially this technique only applied to the detection of lines in an image, later extended to identify any Figure that he could describe with a few parameters; commonly circles and ellipses. The Hough transform belongs to the Group of border-based segmentation techniques. Segmentation is carried out through the detection of the boundaries of each region, i.e., detecting the edges of the image. It is a very robust technique against noise and to the existence of gaps in the border of the object. In the application of the Hough transform to an image, it is necessary to first obtain a binary image (usually in black and white) pixels which form part of the border of the object.

\subsubsection{Admission}

The last step is recognition. So, it is necessary to make the interpretation of the input data. This is accomplished through the establishment of a correspondence of the obtained images through the previous process attributes.

\subsubsection{Statistical pattern recognition}

Basically, it consists of searching within a parameter space, class or model closest to the object in the image description.

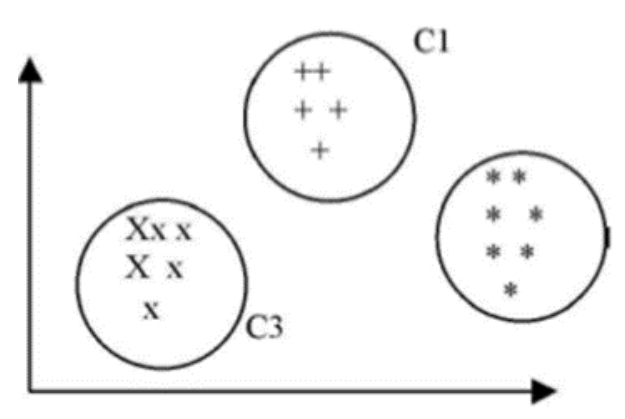

Figure 3 Parameter space with two parameters and three classes

\section{Methodology}

\subsection{Application developtment}

The following software was used to develop the progrm:

$\begin{array}{ll}- & \text { Python } 3.7 \\ - & \text { OpenCv } \\ - & \text { PyQT5 }\end{array}$


The general operation is presented in the next Figure:

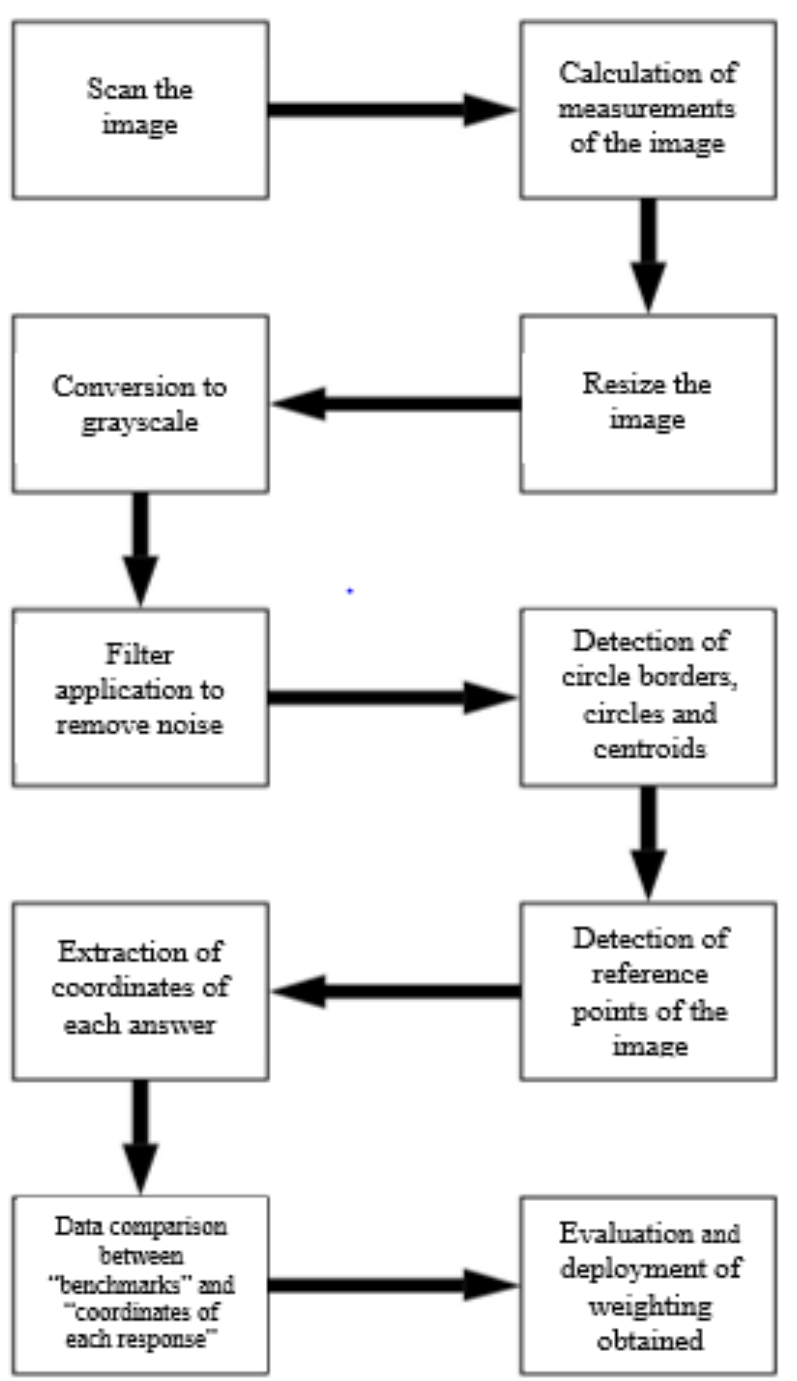

Figure 4 General operation

Taking advantage of the capabilities of smartphones, is made using one for taking pictures of the answer sheets, each response sheet has used reference marks the user is to be guided to take the picture as seen in Figure 5 and the photographic You afías include the field of answers that you want to evaluate.

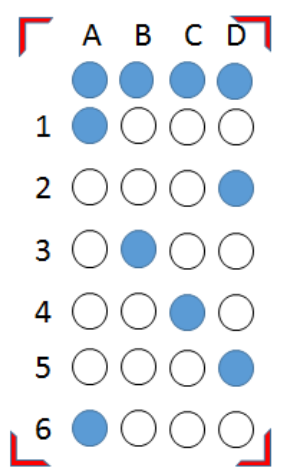

Figure 5 Answer, the red marks are the visual reference for the software
They must meet certain conditions to make the evaluations properly, it is necessary to establish a format of image with good resolution that allows better analyze photography, scale the image to a suitable size and orient correctly the image, that's taken the following assumptions:

- $\quad$ The provided template will be used

- $\quad$ All circles are filled in its entirety

- $\quad$ The image taken will possess a proper orientation

The image is obtained using the reference marks on the answer sheet and begins processing to retrieve information, the Hough transform is used to detect circles formed by the answers, this transformed works best when there is few elements in the picture, that's why it applies a filter media and anti-aliasing that degrades the elements formed by thin lines such as the circles without refilling so Hough transformed, not take them into account; Subsequently, each detected circle is calculated as its centroid (see Figure 6).

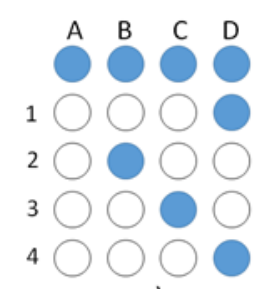

a)

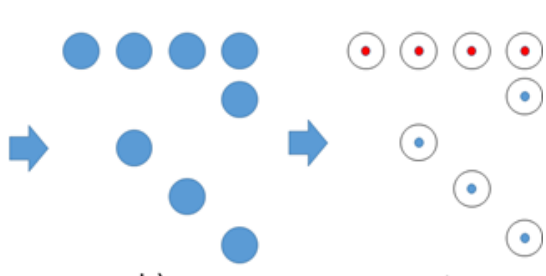

b)

c)

Figure 6 a) image of the obtained answer sheet. b) answer after the filter sheet to highlight circles and blur thin lines. c) calculated in each detected circle centroid

\section{Results}

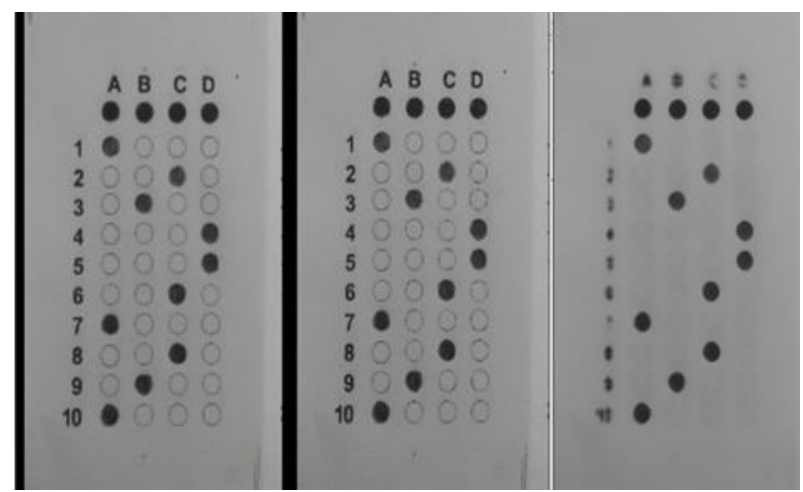

Figure 7 a) Picture of the answer sheet that the program receives as input. b) original image converted to grayscale. c) image in grayscale with median filter

With the aim of making this process easier and more intuitive for the user, created a GUI where the user enters the image of responses and the image of the correct answers to compare them and qualify (see Figure 8).

URUETA, Daniel, RÍOS, David, ALANÍS, Reynaldo and MOTA, Juan. Simple Test Evaluator based on multiple choice questions for Universities with a limited Budget. Journal-Republic of Colombia. 2019 


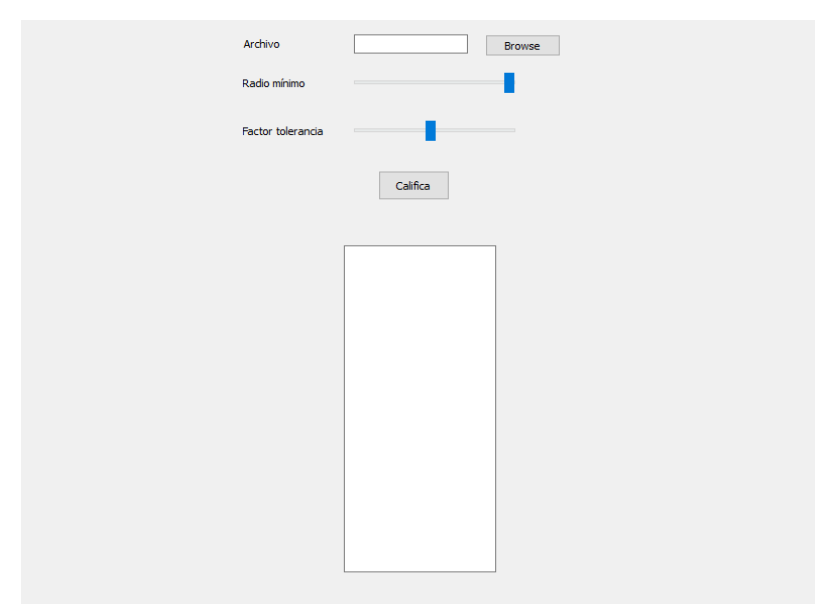

Figure 8 System graphical interface

The program extracts information about the answers chosen, and can add a factor of tolerance to the position to improve the detection of the response, a minimum radius giving the possibility of detecting smaller circles (see Figure 9).

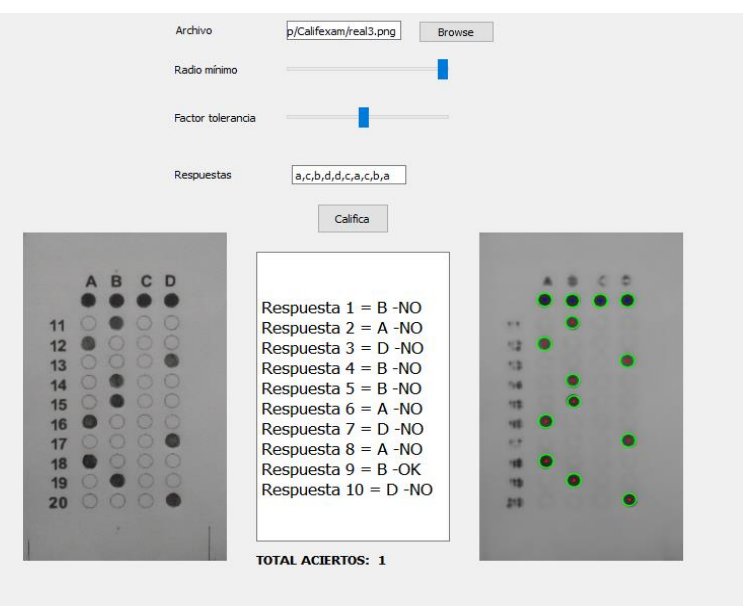

Figure 9 Running Software

\section{Conclusions}

While traditional qualification processes with a scanner are faster and more efficient, the use of techniques of optical recognition by a computer software for the evaluation of answer sheets is an excellent choice of low-cost when It is obtain assessments; This since free software tools were used. Due to its simplicity, it is possible that anyone with basic knowledge can do a deployment with the methodology shown. As enhancement to the system, should be expanded the conditions under which the program recognizes the answers on the answer sheet, also raises the possibility to migrate to mobile devices in which will be allowed to take the picture and make the real-time evaluation.

\section{References}

Estructura de un formulario de lectura óptica. (s/f). Recuperado el 20 de octubre de 2018, de http://www.omrforms.es/estructuraformulariole cturaoptica.html

Segmentación Transformada de Hough. (s/f). Recuperado el 20 de octubre de 2018, de http://www4.ujaen.es/ satorres/practicas/practi ca4_vc.pdf

Procesamiento y Análisis de Señales e Imágenes. (s/f). Recuperado el 20 de octubre de 2018, de http://www.academicos.ccadet.unam.mx/jorge. marquez/cursos/imagenes_neurobiomed/Media na_filtro.pdf. 